\title{
IMPACT OF LOCKDOWN AND SERVICE CONDITIONS ON DAILY HASSLES AND DEPRESSION: A DEVELOPMENTAL ANALYSIS
}

KEY WORDS: lockdown, daily hassles, depression

\section{Himanshi Joshi*}

\section{Prof. Aradhana} Shukla
Department of Psychology, Christ (Deemed to be) University, Delhi NCR. *Corresponding Author

Department of Psychology, Christ (Deemed to be) University, Delhi NCR.

This study was aimed to ascertain the impact of lockdown and service conditions on daily hassles and depression from a developmental perspective. It was contended that (1) variation in each would cause variation in the magnitude of daily hassles and depression (2) employed women would feel more hassles and depression as compared to those who were only homemakers and (3) the period of lockdown would evince more depression as compared to pre- lockdown period. 240 participants ranging between 30-50 years of age were taken into consideration and they were held from Almora and

번 Haldwani, cities of Uttarakhand.

Participants were arranged according to the requirements of $2 \times 2 \times 2$ factorial design with 2 levels of age ( $30-35$ years and 45-50 years), 2 types of service conditions (employed and unemployed), and 2 types of the time period (pre-lockdown and during lockdown) i.e. 30 participants per cell. Depression scale by Shamim \& Tiwari and Daily hazels scale by Shukla \& Joshi were used. Data collection was done individually/ in-group as for the availability of the participants. Data were analyzed by 3-way Analysis of Variance and it was noted that depression and daily hassles were increased with advancing age and during the lockdown period. Moreover, it was also found that employed women faced more depression and daily hassles as compared to homemakers.

Findings were interpreted in terms of chronological age, service conditions, and time period as effectors of daily hazels and depression. At last, recommendations were made to minimize the magnitude of daily hazels and depression in women.

\section{INTRODUCTION}

The COVID-19 catastrophe has put an end to the livelihood of workers around the world. As the pandemic escalated and social distancing occurred, employees lost employment (Beer, 2020; Tozzi, 2020), faced job instability (Blustein et al., 2020), lost distinctions between work and home (Fisher et al., 2020), and became concerned about their wellbeing along with that of their families (Prime,Wade, \& Browne, 2020). Fairly quickly, employees started teleworking, many for the first time (Kramer \& Kramer, 2020). Such changes are likely to have had an effect on work-family (WF) conflict (i.e. incompatibility between work and family; Greenhaus \& Beutell, 1985) and development (i.e. optimistic spillover between work and family; Greenhaus \& Powell, 2006) associated with employee attitudes and actions (Amstad, Meier, Fasel, Elfering, \& Semmer, 2011; McNall, Nicklin, \& Masuda, 2010). It is, therefore, crucial to recognize variables that have an effect on changes in the WF interface throughout this macro crisis and the consequences for attitudes and actions of employees.

Since the magnitude and impact of the pandemic on the WF interface are uncertain, crucial questions abound:What were the usual trends of WF conflict and pre-pandemic enrichment? How did trends change throughout this incident? Although some individuals may be worse off (i.e., more conflict and/or less enrichment), are others better off (i.e., less conflict and/or more enrichment)? What personal and job variables predict changes to the WF interface following the onset of COVID-19? Finally, what are the consequences for workers' attitudes and behaviors of these profile changes during the COVID-19 event?

The correlation of such personality characteristics with depressive disorders was proposed earlier this century (Kraepelin, 1921; Kretschmer, 1936; Schneider, 1958). Since then, several aspects of personality have been observed in the context of major depression (MD), including psychoanalytical (Chodoff, 1972), behavioral (Lewinsohn, 1974), and interpersonal (Hirschfeld et al., 1983) theories. This association between personality and MD has been clarified in terms of various models, such as (1) personality may predispose individuals to MD; or (2) MD may trigger a permanent shift in personality (for a more comprehensive review, see Klein et al. 1993). The first possibility is of special interest. A personality construct that is specifically defined as underlying MD offers a window to MD etiologies. In addition, identifying what personality traits impart risk on MD could provide a more reasonable basis for targeted preventive measures. As a result, several authors have established theories that explain personality dimensions that are likely to represent MD susceptibility. Some prominent cognitive theories claim that self-esteem (SE) is a personality trait that better represents MD vulnerability. (Beck, 1967; Brown and Harris, 1978). Negative self-views are among the three components of Beck's depressive triad' (Beck, 1974).

Abramson et al. (1978) propose that the allocation of control loss to internal, stable and environments leads to low $\mathrm{SE}$ and thus predisposes MD. Brown \& Harris (1978) suggest a model in which low SE enhances the generalization of hopelessness and inability to overcome grief in response to a provoking agent, which may lead to MD. Despite the popularity of these MD etiological hypotheses, research that tested SE's capacity to forecast MD's onsets were likely to result in contradictory results (Lewinsohn et al. 1981; Brown et al. 1986; Hokanson et al. 1989; Robertson \& Simons, 1989). Other studies indicate that the personality construct most closely linked to the risk of MD is neuroticism (N) (Parker, 1980; Enns \& Cox, 1997). Initially envisioned by Eysenck (Eysenck \& Eysenck, 1975), N is designed to assess a person's mental or emotional dysfunction and sensitivity to stress. All studies addressing this issue have shown that $\mathrm{N}$ or $\mathrm{N}$-like traits predict future $\mathrm{MD}$ episodes. (Nystrom and Lindegard, 1975; Angst \& Clayton, 1986; Hirschfeld et al., 1989; Boyce et al., 1991; Kendler et al., 1993). In addition, three of these studies have shown that $N$ predicts first-time MD (Hirschfeld et al. 1989; Boyce et al. 1991, Kendler et al. 1993). Our aim is to compare SE and N directly as risk indices for MD. Using multiple waves of twin data from a population-based twin registry, we approach this issue from a number of complementary viewpoints, including crosssectional and longitudinal epidemiological analyses and twin model fittings.

There are several existing typologies of dual-earner couples 
in the literature and they differ in the focal variable used to categorize couples, including job and family life (Yogev \& Brett, 1985), family identity (Masterson \& Hoobler, 2015), future aspirations (Becker \& Moen, 1999; Pixley, 2008), childcare hours, domestic chores and/or paid work for each partner (Hall \& MacDermid, 2009; Kitterød \& Lappegård, 2012; Sweet \& Moen, 2006).

Recurring threads through typologies include some of the following versions: (a) both people are highly devoted to work and family needs and may rely on appropriate tactics, such as outsourcing, lowering performance standards, or reducing sleep time; (b) asymmetrical strategies involving one person who devotes more time to work (family) while the other one devotes more time to the other, (c) and one person who takes on the bulk of family work while not moving back to work. The latter two techniques are strongly genderedusually, a woman who scales back to work or takes a "second shift"-and they represent a significant proportion of couples in most studies. On the other hand, the characteristics specific to COVID-19 are based on other theoretical principles that provide the opportunity for future strategies. The idea that men and women can and should be assigned to (or retain main responsibility for) work and home roles are profoundly embedded in social norms across the globe (e.g., the principle of 'separate spheres'; Davis \& Greenstein, 2009; Kerber, 1988).

However, the situational conditions raised by the pandemic have the potential to disrupt these standards for a number of reasons. First, the limitation of travel enforced by the pandemic implied that work and home were no longer separate spaces; the sharp rise in working remotely led to a sharp decline in physical boundaries between work and home. This meant that many men were no longer able to leave their homes for work and were therefore physically attached to their families. Meal planning and the emotional and physical needs of children may be more immediate to men than ever before. Second, the pandemic presented couples with a significant and immediate decision-making framework, often requiring drastic changes to the work arrangements of both spouses. This background is significantly different from previously learned decisions, such as whether a partner should take up a new job or a partner who is responsible for taking up a sick child since it directly includes both the jobs of the partners and home life. The possibility that work and home could be separate areas for men and women might have been entirely interrupted by the pandemic and thus make an obvious difference possible.

Keeping these views in consideration, this study was planned and it was contended that; (1) variation in each would cause variation in the magnitude of daily hassles and depression (2) employed women would feel more hassles and depression as compared to those who were only homemakers and (3) the period of lockdown would evince more depression as compared to pre-lockdown period.

In order to check these objectives, this study was planned.

\section{METHOD}

\section{Sample}

240 participants ranging between 30 - 50 years of age were taken into consideration and they were held from Almora and Haldwani, cities of Uttarakhand. Participants were arranged according to the requirements of $2 \times 2 \times 2$ factorial design with 2 levels of age ( $30-35$ years and 45-50 years), 2 types of service conditions (employed and unemployed), and 2 types of the time period (pre-lockdown and during lockdown).

\section{Measures}

In this study, two measures were taken and they are described below-

|www.worldwidejournals.com $\mid$

\section{Depression scale}

This is developed by Shamim Quareem and Roma Tiwari. It has 955 point items and deals with the concept, determinant, and causes of depression. The score ranges between 95- 475. A low score indicates a low level of depression and a high score vice versa. This major is used in many studies related to depression.

\section{Routine stress scale}

Developed by Shukla and Joshi(2005). This scale has 405 point items representing the manifolds of everyday problems of women that create a sense of the problem in them. The score ranges from 40-200. A low score indicates a high experience of routine stress and a high score vice-e versa. This measure is used in many studies of personality development.

\section{Procedure}

Data collection was made after a proper rapport. It was done individually/in-group as per the convenience of the participants. Best efforts were made to avoid external distractions.

\section{RESULT AND DISCUSSION}

Data were analyzed by mean values and t-test and they are presented in Table 2 .

Table 2 Mean values showing the difference in employed and unemployed women's daily hassle and depression.

\begin{tabular}{|l|l|l|l|l|}
\hline $\begin{array}{l}\text { Name of } \\
\text { the scale }\end{array}$ & Employed & Unemployed & & \\
\hline $\begin{array}{l}\text { Daily hassle } \\
\text { Scale }\end{array}$ & 218.20 & 191.6 & T value=6.60 & $P<0.01$ \\
\hline $\begin{array}{l}\text { Depression } \\
\text { scale }\end{array}$ & 179.60 & 208.94 & T value= 5.99 & $P<0.01$ \\
\hline
\end{tabular}

A close perusal of the table reveals that the employed women showed more experience of stress than the unemployed women. It may be due to their stressful schedule related to work from home and dealing with partners and kids at one time . Moreover, it was also seen in the lockdown period that all the chores related with households were performed by the women alone due to lack of supportive staff. Also it was noticed that ego clashes drastically raised during that time. Women had a lot of work to do and in most cases, men did not agree to support them in performing their households. Perhaps, this has caused our findings. Our findings are enclosed in consensus with Joshi (2005) and Mehra(2009).

Our next move was related with the patterns of depression in women as affected by their type of employment. It was noted that unemployed women were found more depressed as compared to employed women. It appears due to the high ego of the husband. Most of the participants were taken from business families and they had a complaint of loss in business during lockdown. Most of the women told in informal interviews that they were also intruded by their husband to make a control on expenses. Perhaps, it has caused our findings.

Findings, in general, indicate that the covid has laid a very serious impact on the society and its footprint are still apparent . It is the need of an hour to keep and maintain an psychophysical health so that we should make our confrontation with the terrible pandemy of covid.

\section{REFERENCES}

1. Allen, T.D., French, K. A., Braun, M.T., \& Fletcher, K. (2019). The passage of time in work-family research: Toward a more dynamic perspective. Journal of Vocational Behavior, 110,245-257. https://doi.org/10.1016/j.jvb.2018.11.013

2. Amstad, F. T., Meier, L. L., Fasel, U., Elfering, A., \& Semmer, N. K. (2011). A metaanalysis of work-family conflict and various outcomes with a special emphasis on cross-domain versus matching-domain relations. Journal of Occupational Health Psychology, 16(2), 151-169. https://doi.org/10.1037/ a0022170

3. Creed, F. H. (1979). Social Origins of Depression: A Study of Psychiatric Disorder in Women. By George W. Brown and Tirril Harris. London: Tavistock Publications.Pp 
4. 374. £12.50. - The Experience of Depression. By Dorothy Rowe. Chichester John Wiley. Pp 270. £10.75, £3.95 (paperback). British Journal of Psychiatry, 134(1), 116.https://doi.org/10.1192/s0007125000199088

5. DeLongis, A., Folkman, S., \& Lazarus, R. S. (1988). The impact of daily stress on health and mood: Psychological and social resources as mediators. Journal of Personality and Social Psychology, 54(3), 486-495. https://doi.org/10.1037/ 0022-3514.54.3.486

6. Hoerger,M., Alonzi,S.,Perry,L.M.,Voss, H.M.,Easwar,S., \& Gerhart, J. I. (2020) Impact of the COVID-19 pandemic on mental health: Real-time surveillance using Google Trends. Psychological Trauma: Theory, Research, Practice, and Policy, 12(6), 567-568.https://doi.org/10.1037/tra0000872

7. Holden, R. (n.d.). Understanding the Relationship between Depression, Hopelessness, 174.

8. Lee, I. S. (2002). Depression and Husband's Support in Married Women. Korean Journal of Women Health Nursing, 8(4), 482. https://doi.org/10.4069/ kjwhn.2002.8.4.482

9. Maji, S. (2018). Society and "good woman": A critical review of gender difference in depression. The International Journal of Social Psychiatry, 64(4), 396-405.https://doi.org/10.1177/0020764018765023

10. Mize, J. \& Kliewer, W. (2017). Domain-Specific Daily Hassles, Anxiety, and Delinquent Behaviors among Low-Income, Urban Youth. Journal of Applied Developmental Psychology, 53, 31-39. https://doi.org/10.1016/j.appdev. 2017.09.003

11. Pietromonaco, P. R., \& Overall, N. C. (2020). Applying relationship science to evaluate how the COVID-19 pandemic may impact couples' relationships. American Psychologist, 1-14.https://doi.org/10.1037/amp0000714

12. Poms, L. W. Fleming, L. C., \& Jacobsen, K. H. (2016). Work-Family Conflict, Stress, and Physical and Mental Health: A Model for Understanding Barriers to and Opportunities for Women's Well-Being at Home and in the Workplace. World Medical \& Health Policy, 8(4), 444-457. https://doi.org/10.1002/wmh3. 211

13. Pondé, M. P., \& Santana, V. S. (2000). Participation in Leisure Activities: Is It a Protective Factor for Women's Mental Health? Journal of Leisure Research, 32(4),457-472.https://doi.org/10.1080/00222216.2000.11949927

14. Prime, H., Wade, M., \& Browne, D. T. (2020). Risk and resilience in family wellbeing during the COVID-19 pandemic. The American Psychologist, 75(5), 631 -643.https://doi.org/10.1037/amp0000660

15. Rettie, H., \& Daniels, J. (2020). Coping and tolerance of uncertainty: Predictors and mediators of mental health during the COVID-19 pandemic. The American Psychologist.https://doi.org/10.1037/amp0000710

16. Roberts, S. B., \& Kendler, K. S. (1999). Neuroticism and self-esteem as indices of the vulnerability to major depression in women. Psychological Medicine, 29(5), 1101-1109.https://doi.org/10.1017/\$0033291799008739

17. Sadock, B. J. (2007). Kaplan \& Sadock's synopsis of psychiatry (10th ed.). Philadelphia, PA:LippincottWilliams \&Wilkins.

18. Schönfeld, P., Brailovskaia, J., Bieda, A., Zhang, X. C., \& Margraf, J. (2016). The effects of daily stress on positive and negative mental health: Mediation through self-efficacy.

19. International Journal of Clinical and Health Psychology: IJCHP, 16(1), 1-10. https://doi.org/10.1016/j.ijchp.2015.08.005

20. Serido, J., Almeida, D. M., \&Wethington, E. (2004). Chronic Stressors and Daily Hassles: Unique and Interactive Relationships with Psychological Distress. Journal of Health and Social Behavior, 45(1), 17-33. https://doi.org/10.1177/ 002214650404500102

21. Shockley, K. M., Clark, M. A., Dodd, H., \& King, E. B. (2021). Work-family strategies during COVID-19: Examining gender dynamics among dualearner couples with young children.Journal of Applied Psychology, 106(1), 1528.http://dx.doi.org/10.1037/apl0000857

22. Trougakos, J. P., Chawla, N., \& McCarthy, J. M. (2020). Working in a pandemic: Exploring the impact of COVID-19 health anxiety on work, family, and health outcomes. Journal of Applied Psychology, 105(11), 1234-1245. https://doi. org/10.1037/apl0000739

23. Vaziri, H., Casper,W.J.,Wayne,J.H., \& Matthews, R. A. (20200831). Changes to the work-family interface during the COVID-19 pandemic: Examining predictors and

24. implications using latent transition analysis. Journal of Applied Psychology, 105(10), 1073.https://doi.org/10.1037/apl0000819 